\title{
AVALIAÇÃO DA REGENERAÇÃO EM ECOSSISTEMAS PERTURBADOS COMO INDICADOR DA RESTAURAÇÃO EM AMBIENTES COM MARCADA ESTACIONALIDADE, NOVA IGUAÇU (RJ)
}

\author{
Cristiane Roppa ${ }^{1}$, Ricardo Valcarcel ${ }^{2}$, Hiram Feijó Baylão Junior ${ }^{3}$ \\ ${ }^{1}$ Eng ${ }^{a}$ Florestal, M.Sc., Doutoranda em Ciências Ambientais e Florestais, UFRRJ, Seropédica, RJ, Brasil - cris_roppa@ yahoo.com.br \\ ${ }^{2}$ Eng. Florestal, Dr., Depto. de Ciências Ambientais, UFRRJ, Seropédica, RJ, Brasil - ricval@ ufrrj.br \\ ${ }^{3}$ Eng. Florestal, M.Sc., Doutorando em Ciências Ambientais e Florestais, UFRRJ, Seropédica, RJ, Brasil - baylaojr@globomail.com
}

Recebido para publicação: 18/08/2011 - Aceito para publicação: 14/02/2012

\begin{abstract}
Resumo
A variação da composição florística e estrutural da regeneração natural $(0,10<$ altura $<3,0 \mathrm{~m}$; $\mathrm{CAP} \leq 15 \mathrm{~cm}$ ) foi avaliada em áreas perturbadas de fragmento florestal secundário em estágio médio e pastagem, em ambiente Estacional Semidecidual de Nova Iguaçu (RJ). O levantamento florístico foi realizado durante período chuvoso $(145 \mathrm{~mm})$ e de estiagem $(15 \mathrm{~mm})$ no ano 2008 , utilizando-se método fitossociológico de pontos. Os resultados evidenciaram a saída de 8 espécies $(37,50 \%$ de trepadeiras e $37,50 \%$ de arbustivas decíduas) na floresta e 7 espécies (71,43\% de herbáceas) na pastagem. A diversidade e o tipo de hábito das espécies regenerantes na floresta sinalizam a adaptação das espécies permanentes ao sistema ecológico com marcado período de estiagem, em que os efeitos climáticos afetam rapidamente as dinâmicas populacionais dos ecossistemas em fase de restauração.

Palavras-chave: Sazonalidade; sucessão vegetal; restauração florestal.
\end{abstract}

\begin{abstract}
Evaluation of regeneration in disturbed ecosystems as indicator of restoration in environments with marked seasonality, Nova Iguaçu $(R J)$. The variation of the floristic and structural composition of the natural regeneration $(0.10<$ height $<3.0 \mathrm{~m} ; \mathrm{CAP} \leq 15 \mathrm{~cm})$ were evaluated in disturbed area of middle stage secondary forest fragment and pasture, in Semideciduous Seasonal Environment of Nova Iguaçu (RJ). The floristic survey was done during rain period $(145 \mathrm{~mm})$ as well as drought $(15 \mathrm{~mm})$ along the year 2008. It was used phytosociology point method. The results evidenced emergency of 8 species (creepers $37.50 \%$ and shrub $37.50 \%$ ) in forest, and 7 species (71.43\% herbaceous) in pasture. Diversity and kind of habit of species in regeneration in the forest point to adaptation of permanent species to the ecological system with marked drought period, as the climatic effects quickly affect population dynamics of the ecosystems in restoration phase.

Keywords: Seasonality; vegetable succession; forest restoration.
\end{abstract}

\section{INTRODUÇÃO}

A restauração florestal de áreas perturbadas objetiva dotar os ecossistemas de meios e condições similares às originais, tanto nos seus aspectos estruturais como funcionais, para que os mesmos possam ofertar características biológicas e físicas que promovam sua autodeterminação (CAIRNS JUNIOR; HECKMAN, 1996; BRASIL, 2000; ENGEL; PARROTTA, 2008; KAGEYAMA; GANDARA, 2005). $\mathrm{Na}$ prática, ela consiste em um conjunto de atividades que induzem o retorno do ecossistema a uma condição autossustentável, tendo como base o estabelecimento e a manutenção dos processos ecológicos (PARKER, 1997; ENGEL; PARROTTA, 2008; RODRIGUES et al., 2007), principalmente através da evolução dos estágios sucessionais, que atuarão como salvaguarda dos estágios subsequentes da restauração.

Os agentes causadores de distúrbios nos ecossistemas, que interferem na regeneração e sucessão, podem ser divididos, em função da sua natureza, em antrópicos e naturais (COATES; BURTON, 1997; 
LARCHER, 2004; DREW, 2005; REIS-DUARTE; GALVÃO-BUENO, 2007), sendo responsáveis por condicionarem diferentes níveis de perturbação. Os ecossistemas perturbados são ambientes que sofreram distúrbio, mas mantiveram meios de regeneração biótica, ou seja, um nível mínimo de resiliência capaz de promover a sua autorregeneração (CARVALHO, 2000; CARPANEZZI, 2005).

As áreas objeto do presente estudo encontram-se na vertente norte da Serra do MadureiraMendanha, onde predomina a formação de Florestas Estacionais Semideciduais (VELOSO, 1992), constituindo um encrave fitogeográfico dentro da Mata Atlântica. Estando submetidas a condições ambientais exíguas, onde prevalece regime irregular de distribuição das chuvas, encostas com rampas longas $(1.000 \mathrm{~m})$, solos rasos, declividade acentuada, exposição do relevo dessecado pela maior incidência solar no período vespertino, baixa interceptação das frentes frias (SPOLIDORO, 1998), que, associadas aos níveis de uso no passado - cana-de-açúcar, café, citricultura, culturas de subsistência, pastagens devolutas e mineração (PREFEITURA MUNICIPAL DE NOVA IGUAÇU - PMNI, 2007) -, colaboraram para a redução da resiliência desses ecossistemas.

Nas florestas decíduas e semidecíduas, os processos ecológicos são fortemente marcados pela sazonalidade climática (BULLOCK, 1995), determinando alterações dinâmicas da vegetação em cada estação (LARCHER, 2004). A sazonalidade climática influencia a abertura do dossel e o índice de área foliar, já que as espécies arbóreas decíduas reagem às variações extremas do ambiente, alterando o microclima do sub-bosque (SATTLER et al., 2007), luminosidade e umidade, regulando e afetando a qualidade da regeneração.

As fases de germinação e estabelecimento de plântulas são etapas críticas no desenvolvimento da regeneração, principalmente para espécies arbóreas, as quais são mais sensíveis às variáveis ambientais (KOZLOWSKI, 2002). Segundo Ribeiro e Felfili (2009), a avaliação da regeneração natural em florestas permite entender o seu funcionamento, orientando ações de manejo e recuperação de áreas degradadas.

Boas condições quantitativas e qualitativas da regeneração possibilitam a preservação, conservação e formação de florestas (GAMA et al., 2003). Respostas observadas no comportamento da regeneração após perturbações em florestas tropicais permitem a constituição de indicadores da restauração, principalmente para as florestas tropicais secas (florestas sazonais) (VIEIRA; SCARIOT, 2006), onde as mudanças das condições ambientais entre a estação chuvosa e seca causam modificações na regeneração (NASCIMENTO et al., 2007).

Este estudo teve como objetivo avaliar a variação da composição florística e estrutural da regeneração natural em ecossistemas perturbados da Mata Attântica, submetidos a níveis de restauração espontânea distintos, em ambientes de domínio ecológico da Floresta Estacional Semidecidual, em Nova Iguaçu (RJ).

\section{MATERIAL E MÉTODOS}

\section{Caracterização da área}

A área de estudo localiza-se na vertente norte da Serra do Madureira-Mendanha, inclusa no maciço Gericinó/Madureira-Mendanha, região metropolitana do Rio de Janeiro, município de Nova Iguaçu (RJ).

O clima, segundo classificação de Köppen, varia entre tropical de altitude (Cwa) e tropical (Aw), nas áreas baixas, ambos caracterizados por verão chuvoso e inverno seco. A média anual de temperatura varia entre 17 e $22{ }^{\circ} \mathrm{C}$ (Cwa) e 22 e $24{ }^{\circ} \mathrm{C}(\mathrm{Aw})$. A precipitação média anual é de $1.212 \mathrm{~mm}$ (MATTOS et al., 1998), ocorrendo de forma mal distribuída ao longo do ano, com períodos de seca entre os meses de maio e setembro e os de maior precipitação entre os meses de outubro a março (FUNDAÇÃO INSTITUTO DE DESENVOLVIMENTO ECONÔMICO E SOCIAL DO RIO DE JANEIRO - FIDERJ, 1978).

Nos altos das serras ocorrem Latossolos Vermelho-Amarelo álicos e Argissolos, predominando os Latossolos Vermelho-Amarelo álicos (SECRETARIA MUNICIAL DE URBANISMO E MEIO AMBIENTE - SEMUAM, 2001), podendo ocorrer associados a Cambissolos e Neossolos Litólicos, com afloramentos rochosos (LUMBRERAS et al., 2003).

\section{Antecedentes de perturbação aos ecossistemas da região}

Em meados do século XVI, chegaram os primeiros colonos europeus, dando início ao conjunto de ciclos econômicos, cujas atividades estiveram interligadas com a supressão da vegetação da Serra do Madureira-Mendanha (PMNI, 2007). 
No início do século XIX, onde anteriormente havia cana-de-açúcar, foram implantados laranjais, que alcançaram sua plenitude econômica na década de trinta (1930-1939), quando Nova Iguaçu foi chamada de "Cidade Perfume". Com a Primeira Guerra Mundial, os laranjais entraram em decrepitude, cedendo lugar a atividades industriais e pastagens (TRIBUNAL DE CONTAS REGIONAL DO ESTADO DO RIO DE JANEIRO (TCE-RJ), 2007). Hoje predominam mineração e pecuária extensiva na vertente norte da serra.

A vegetação original pertence ao domínio ecológico da Mata Atlântica e ocupou todo o maciço. Ela foi praticamente dizimada nos locais onde houve caminhos/carreadores para os plantios da citricultura, permanecendo apenas os remanescentes florestais nos topos de morros e em locais de difícil acesso.

$\mathrm{Na}$ vertente sul, devido à maior oferta de umidade, houve o predomínio da restauração espontânea da vegetação, enquanto na vertente norte predominou a tendência de degradação. Nesta vertente, alguns fragmentos florestais menos resilientes ainda continuam sendo atingidos por queimadas nas bordas, transformando-se em pastagens.

\section{Avaliação da regeneração natural}

Para a realização do estudo, foram selecionadas duas áreas, dentro de uma microbacia hidrográfica, uma com pastagem e outra com floresta secundária em estágio médio, cujo meio físico apresenta declividade média, ângulo de incidência de ventos, exposição solar, orientação do fluxo de escoamento, comprimento de rampa, profundidade do solo e proximidade de acessos similares (CORTINES, 2005).

$\mathrm{Na}$ microbacia predomina pastagem (25 ha) sem manejo, constituídas por Panicum maximum Jacq. submetidas a queimadas frequentes (SPOLIDORO, 1998). Os fragmentos de floresta secundária $(4,4$ ha) pertencem à formação da Floresta Estacional Semidecidual Submontana (INSTITUTO BRASILEIRO DE GEOGRAFIA E ESTATÍSTICA (IBGE), 1992), com mais de 100 anos sem exploração, localizada em cota $245 \mathrm{~m}$ acima da área de pastagem.

O levantamento florístico da regeneração espontânea no verão (final de fevereiro) e inverno (final de julho) feito em 2008 foi realizado em parcela permanente de $100 \mathrm{~m}^{2}(10 \times 10 \mathrm{~m})$, utilizando-se método de pontos (COCKAINE, 1926, adaptado por MANTOVANI, 1987). O procedimento consistiu em apoiar verticalmente uma vara graduada de $3 \mathrm{~m}$ de altura em pontos equidistantes um metro entre si. Nos pontos, considerou-se como critério para inclusão plantas com altura entre $10 \mathrm{~cm}$ e $3 \mathrm{~m}$ e CAP (circunferência à altura do peito) $\leq 15 \mathrm{~cm}$, das quais se registrou a espécie, número de vezes que a espécie tocava na vara e altura da planta.

Para analisar a variação sazonal (verão-inverno) das espécies, foram utilizadas curvas espécieponto. Elas foram ajustadas em função dos modelos de regressão linear e logarítmico (GUEDES-BRUNI, 1998). A área de pastagem, no período de inverno, sofreu ação do fogo, fato usual na região, permanecendo com apenas um levantamento, uma vez que as espécies foram suprimidas acima da superfície do solo.

As espécies não identificadas em campo foram coletadas, herborizadas e identificadas por meio de comparação com exsicatas no Herbário do Departamento de Botânica da UFRRJ e com o apoio de especialistas. As espécies foram classificadas de acordo com o sistema Angiosperm Phylogeny Group (APG) II (2003).

A estrutura da regeneração foi avaliada através dos parâmetros fitossociológicos de Densidade Relativa (DR), Vigor Absoluto (VA), Vigor Relativo (VR), Frequência Absoluta (FA) e Frequência Relativa (FR), conforme Matteucci e Colma (1982). O valor de importância foi calculado por VI = FR + DR + VR (CURTIS, 1959). A diversidade foi avaliada pelo índice de Shannon (H') e a similaridade pelo índice de Sorensen (S) (KREBS, 1978).

As espécies arbóreas e arbustivas foram classificadas, de acordo com seu grupo ecológico, em Pioneiras (PI), Secundárias Iniciais (SI), Secundárias Tardias (ST) e Não Classificadas ou Caracterizadas (NC). Adotou-se a classificação de Gandolfi et al. (1995), por ser o sistema que mais se aproxima das características das florestas secundárias semidecíduas.

Para acompanhar a variação mensal de precipitação, temperatura e umidade relativa do ar, foram utilizados dados de estação meteorológica (WMR928N data logger), localizada a $2 \mathrm{~km}$ da área de estudo. Foram analisadas medidas registradas em intervalos de um minuto (temperatura e umidade), no período de 365 dias (outubro/2007-setembro/2008). Para determinar a precipitação mensal, foram somados os 
valores de precipitação diária, e para a temperatura e umidade relativa foi realizada a média diária e posteriormente a média mensal, totalizando uma série de 525.600 medidas de temperatura e 525.600 de umidade relativa.

\section{RESULTADOS E DISCUSSÃO}

\section{Composição florística e estrutura da regeneração}

Foram amostrados 349 indivíduos na regeneração para o período de verão e 146 para o inverno. As famílias botânicas mais representativas foram Fabaceae e Asteraceae, respectivamente, com $20 \%$ e $10 \%$ das espécies. Ao total foram amostradas 14 famílias, distribuídas em 22 gêneros e 30 espécies (Tabela 1).

Tabela 1. Espécies amostradas nas áreas de pastagem e floresta. GE: grupo ecológico; PI: pioneiras; SI: secundária inicial; ST: secundária tardia; e NC: não classificada; V: verão; I: inverno.

Table 1. Surveyed species on pasture and forestry areas. GE: ecological group; PI: pioneer; SI: initial secondary; ST: late secondary; and NC: no classified. V: Summer; I: Winter.

\begin{tabular}{|c|c|c|c|c|c|}
\hline Família/Nome científico & Nome vulgar & Hábito & Pastagem & Floresta & GE \\
\hline \multicolumn{6}{|l|}{ ALSTROEMERIACEAE } \\
\hline \multirow{2}{*}{\multicolumn{6}{|c|}{ APOCYNACEAE }} \\
\hline & & & & & \\
\hline Morfoespécie 11 & - & Trepadeira & & I & \\
\hline \multicolumn{6}{|l|}{ ASTERACEAE } \\
\hline $\begin{array}{l}\text { Orthopappus angustifolius (Sw.) } \\
\text { Gleason }\end{array}$ & - & Herbácea & $\mathrm{V}$ & & \\
\hline Pterocaulon virgatum (L.) DC. & - & Herbácea & $\mathrm{V}$ & & \\
\hline Morfoespécie 01 & - & Herbácea & $\mathrm{V}$ & VI & \\
\hline \multicolumn{6}{|l|}{ BIGNONIACEAE } \\
\hline Pyrostegia venusta Miers. & Cipó-de-são-joão & Trepadeira & & VI & \\
\hline $\begin{array}{l}\text { Handroanthus cf. umbellata (Sond.) } \\
\text { Mattos }\end{array}$ & Ipê-amarelo & Arbórea & & VI & $\mathrm{P}$ \\
\hline \multicolumn{6}{|l|}{ BROMELIACEAE } \\
\hline Bromelia antiacantha Bertol. & Bromélia & Herbácea & & VI & \\
\hline Crypthantus sp. & Bromélia & Herbácea & & VI & \\
\hline \multicolumn{6}{|l|}{ ERYTHROXYLACEAE } \\
\hline $\begin{array}{l}\text { Erythroxilum pulchrum St.-Hil. } \\
\text { EUPHORBIACEAE }\end{array}$ & Arco-de-pipa & Arbórea & & VI & SI \\
\hline Croton sp. & - & Arbustiva & & V & $\mathrm{P}$ \\
\hline \multicolumn{6}{|l|}{ FABACEAE-MIMOSOIDEAE } \\
\hline Acacia plumosa Lowe & Arranha-gato & Trepadeira & & VI & \\
\hline Desmodium barbatum (L.) Benth & Barbadinho & Herbácea & $\mathrm{V}$ & & \\
\hline Samanea sp. & - & Arbórea & & VI & $\mathrm{P}$ \\
\hline \multicolumn{6}{|l|}{ FABACEAE-FABOIDEAE } \\
\hline Dalbergia brasiliensis Vogel & Caroba-brava & Arbórea & & I & SI \\
\hline Machaerium sp. & - & Trepadeira & & VI & \\
\hline Myrocarpus fastigiatus Allemao & Óleo-pardo & Arbórea & & VI & SI \\
\hline Vigna sp. & - & Trepadeira & $\mathrm{V}$ & & \\
\hline \multicolumn{6}{|l|}{ MORACEAE } \\
\hline $\begin{array}{l}\text { Brosimum guianense (Aubl.) Huber } \\
\text { MYRTACEAE }\end{array}$ & \multicolumn{4}{|c|}{ MYRTACEAE } & ST \\
\hline \multicolumn{5}{|l|}{ ORCHIDACEAE } & SI \\
\hline $\begin{array}{l}\text { Oeceoclades maculata (Lindl.) Lindl. } \\
\text { POACEAE }\end{array}$ & Orquídea & Herbácea & & VI & \\
\hline Olyra sp. & Bambu & Gramínea & & $\mathrm{V}$ & \\
\hline Panicum maximum Jacq. & Capim-colonião & Gramínea & $\mathrm{V}$ & & \\
\hline
\end{tabular}




\begin{tabular}{llcl}
\hline SAPINDACEAE & & & \\
Serjania clematidifolia Camberg. & - & Trepadeira & VI \\
Serjania sp. & - & Trepadeira & V \\
SOLANACEAE & Joá-bravo & Herbácea & V \\
Solanum palinacanthum Dunal & & & \\
Não identificadas & - & Trepadeira & I \\
Morfoespécie 02 & & Arbustiva & V \\
Morfoespécie 06 & - & Herbácea & V \\
Morfoespécie 07 & & Arbustiva & V \\
Morfoespécie 08 & & & NC \\
\hline
\end{tabular}

Quanto ao hábito, as espécies amostradas na regeneração distribuíram-se em trepadeira (33,33\%), herbácea $(26,67 \%)$, arbórea $(23,33 \%)$, arbustiva $(10,00 \%)$ e gramínea $(6,67 \%)$. O predomínio de espécies do grupo das trepadeiras pode ser explicado pela sua riqueza na vegetação tropical, sendo favorecidas nesses hábitats, com exceção daqueles muito secos, frios ou com solo muito pobre (JANZEN, 1980).

A floresta apresentou 41,67\% de espécies nos grupos arbóreo/arbustivo e 37,50\% para o grupo das trepadeiras (Figura 1). As trepadeiras, geralmente, ocorrem em fragmentos de florestas, como resultado de perturbações, porém em Florestas Semideciduais são comuns e apresentam importantes funções ecológicas: a) aumentam a diversidade biológica; b) aumentam a biomassa, por reproduzirem-se rapidamente nas estações chuvosa e perderem folhas na estação seca (JANZEN, 1980); c) contribuem com os mecanismos de ciclagem de nutrientes; e d) apresentam floração ao longo do ano, que atraem insetos polinizadores, aumentando a complexidade do ecossistema. Essas características também lhes conferem vantagens para sobreviver nesse tipo de ambiente.
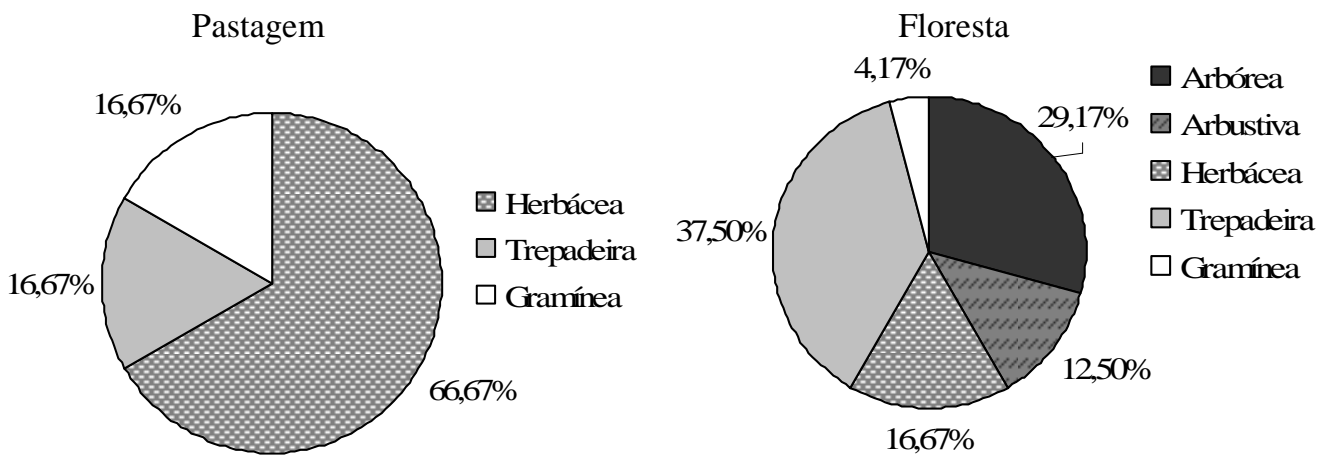

Figura 1. Distribuição por hábito para as espécies da regeneração amostradas na pastagem e na área de floresta, nos períodos de verão e inverno, 2008.

Figure 1. Habit distribution of regenerated species surveyed in pasture and forest areas, in Summer and Winter periods, 2008.

A distribuição da regeneração na floresta em cinco hábitos (Figura 1), com equilíbrio entre eles e a presença de espécies pertencentes a todos os grupos ecológicos, inclusive com uma secundária tardia (Brosimum guianense (Aubl.) Huber) e uma espécie rara (Eugenia brasiliensis Lam.), indica que essa área se apresenta estruturalmente mais avançada, considerando o pequeno tamanho da área amostral.

As três principais espécies com maior VI, para o período de verão, na pastagem foram Panicum maximum Jacq., Desmodium barbatum (L.) Benth. e Solanum paniculathum Dunal, com 208,52, 32,61 e $28,53 \%$ de VI, respectivamente (Tabela 2). Essas espécies são resistentes às condições ambientais desfavoráveis, conseguindo se reproduzir após a ocorrência de fogo, temperaturas elevadas e escassez de água e minerais.

A baixa diversidade de espécies da área de pastagem indica que $P$. maximum pode estar impedindo a entrada de outras espécies mais exigentes. Esse processo pode estar sendo intensificado pela presença do fogo, que tem ocorrido com frequência mínima de uma vez ao ano, pois ele é um fator prejudicial à regeneração e ao banco de sementes do solo (POGGIANI et al., 1983; ROSOT et al., 2007). 
Tabela 2. Parâmetros quantitativos da regeneração espontânea na pastagem, para o período do verão/2008. $\mathrm{n}=$ número de indivíduos da espécie; $\mathrm{N}=$ número total de indivíduos; $\mathrm{NT}=$ número de toques; $\mathrm{NP}=$ número de pontos; $\mathrm{DR}=$ densidade relativa; $\mathrm{VA}=$ vigor absoluto; $\mathrm{VR}=$ vigor relativo; $\mathrm{MT}=$ média de toques; $\mathrm{FA}=$ frequência absoluta; $\mathrm{FR}=$ frequência relativa; $\mathrm{VI}=$ valor de importância.

Table 2. Quantitative parameters of spontaneous regeneration in pasture, for the Summer period /2008. $\mathrm{n}=$ number of species individuals; $\mathrm{N}=$ total number of individuals; $\mathrm{NT}=$ number of touches; $\mathrm{NP}=$ number of points; $\mathrm{DR}=$ relative density; $\mathrm{VA}=$ absolute vigor; $\mathrm{VR}=$ relative vigor; $\mathrm{MT}=$ average of touches; $\mathrm{FA}=$ absolute frequency; $\mathrm{FR}=$ relative frequency; $\mathrm{VI}=$ importance value.

\begin{tabular}{lcccccccccccc}
\hline Espécie & n & N & NT & NTP & NP & DR & VA & VR & MT & FA & FR & VI \\
\hline Panicum maximum & 100 & 163 & 581 & 100 & 100 & 61,35 & 581,0 & 85,82 & 5,81 & 100,00 & 61,35 & 208,52 \\
Desmodium barbatum & 22 & 163 & 38 & 100 & 22 & 13,50 & 38,00 & 5,61 & 1,73 & 22,00 & 13,50 & 32,61 \\
Solanum palinacanthum & 20 & 163 & 27 & 100 & 20 & 12,27 & 27,00 & 3,99 & 1,35 & 20,00 & 12,27 & 28,53 \\
Aeschynomene sp. & 10 & 163 & 15 & 100 & 10 & 6,13 & 15,00 & 2,22 & 1,50 & 10,00 & 6,13 & 14,49 \\
Vigna sp. & 7 & 163 & 8 & 100 & 7 & 4,29 & 8,00 & 1,18 & 1,14 & 7,00 & 4,29 & 9,77 \\
Orthopappus angustifolius & 2 & 163 & 2 & 100 & 2 & 1,23 & 2,00 & 0,30 & 1,00 & 2,00 & 1,23 & 2,75 \\
Pterocaulon virgatum & 1 & 163 & 4 & 100 & 1 & 0,61 & 4,00 & 0,59 & 4,00 & 1,00 & 0,61 & 1,82 \\
Morfoespécie 01 & 1 & 163 & 2 & 100 & 1 & 0,61 & 2,00 & 0,30 & 2,00 & 1,00 & 0,61 & 1,52 \\
\hline
\end{tabular}

Na floresta, as espécies com maior VI, no período de verão, foram B. guianense, Samanea sp. e Serjania sp., respectivamente, com 148,30, 37,79 e 19,31\% (Tabela 3), enquanto no período de inverno destacaram-se B. guianense, Samanea sp. e Acacia plumosa Lowe, com 162,97, 33,17 e 21,56\% do VI, respectivamente (Tabela 4). A ocorrência de maior VI para B. guianense pode ter sido favorecida pela sua distribuição abundante na área (LORENZI, 2002). Eugenia brasiliensis Lam., que apareceu em quinto lugar, está bem representada dentro desse ecossistema. Segundo Lorenzi (2002), essa espécie possui regeneração natural limitada e é de ocorrência rara.

Os valores encontrados para o índice de diversidade de Shannon (H') variaram de acordo com a sazonalidade das estações. Para o pasto foi de 1,25 (verão) e para a floresta de 1,99 (verão) e 1,78 (inverno). Os valores mostraram que mesmo no inverno a diversidade permaneceu maior para a floresta, indicando o nível de resistência adquirido pelas espécies desse ambiente, tornando-as capaz de permanecer no ecossistema mesmo na estação menos favorável.

Em Floresta Estacional Decidual no Rio Grande do Sul, Vaccaro et al. (1999) encontraram índice de diversidade (H') de 2,91, 2,75 e 2,72, respectivamente, para capoeirão, floresta secundária e floresta madura, considerando um DAP $\geq 10$. Silva et al. (2004), para mata de galeria semidecidual, encontraram 2,89. Martins et al. (2008), avaliando a vegetação de Floresta Estacional Semidecidual em Minas Gerais, considerando indivíduos acima de $1,00 \mathrm{~m}$ e DAP $\leq 5 \mathrm{~cm}$, encontraram diversidade variando entre 1,39 e 3,01 no entorno de clareiras e de 1,02 a 3,01 dentro das clareiras.

O índice de diversidade encontra-se abaixo da média para a pastagem $(1,25)$, enquanto que para a floresta se aproxima dos valores observados na literatura. Estes, em ambas as áreas, devem ter sido influenciados pelo caráter marcante das características ambientais da região, com forte influência da sazonalidade.

A similaridade obtida entre as áreas de pastagem e floresta foi de 42,00\%. Vaccaro et al. (1999), estudando três subseres de uma Floresta Estacional Decidual, encontraram valores de 45,00, 55,81 e $60,00 \%$, considerados baixos. Comparativamente, os resultados do presente estudo também foram baixos, indicando que predominam características divergentes nesses ambientes (áreas de pastagem e floresta), tornando-os estrutural e floristicamente distintos. Isso pode indicar que as características do ecossistema com pastagem estão se afastando daquelas apresentadas pela floresta, ou seja, provavelmente ele não está conseguindo manter os processos ecológicos responsáveis por criar tendência de restauração espontânea.

\section{Variação sazonal da colonização}

A densidade e a diversidade das espécies em regeneração variaram sazonalmente, recebendo influência dos períodos de maior (verão) e menor precipitação (inverno) (Figura 2). 
Tabela 3. Parâmetros quantitativos da regeneração espontânea da floresta, para o período do verão/2008. n: número de indivíduos da espécie; N: número total de indivíduos; NT: número de toques; NP: número de pontos; DR: densidade relativa; VA: vigor absoluto; VR: vigor relativo; MT: média de toques; FA: frequência absoluta; FR: frequência relativa; VI: valor de importância.

Table 3. Quantitative parameters of spontaneous regeneration in the forestry, on the Summer period/2008. n: number of species individuals; $\mathrm{N}$ : total individuals number; NT: number of touches; NP: number of points; DR: relative density; VA: absolute vigor; VR: relative vigor; MT: average of touches; FA: absolute frequency; FR: relative frequency; VI: importance value.

\begin{tabular}{lcccccccccccc}
\hline Espécie & $\mathbf{n}$ & $\mathbf{N}$ & $\mathbf{N T}$ & $\mathbf{N T P}$ & $\mathbf{N P}$ & $\mathbf{D R}$ & $\mathbf{V A}$ & $\mathbf{V R}$ & $\mathbf{M T}$ & FA & FR & VI \\
\hline Brosimum guianense & 93 & 186 & 251 & 101 & 73 & 50,00 & 248,51 & 54,33 & 3,44 & 72,28 & 43,97 & 148,30 \\
Samanea sp. & 21 & 186 & 64 & 101 & 21 & 11,29 & 63,37 & 13,85 & 3,05 & 20,79 & 12,65 & 37,79 \\
Serjania sp. & 12 & 186 & 26 & 101 & 12 & 6,45 & 25,74 & 5,63 & 2,17 & 11,88 & 7,23 & 19,31 \\
Acacia plumosa & 11 & 186 & 22 & 101 & 11 & 5,91 & 21,78 & 4,76 & 2,00 & 10,89 & 6,63 & 17,30 \\
Eugenia brasiliensis & 6 & 186 & 16 & 101 & 6 & 3,23 & 15,84 & 3,46 & 2,67 & 5,94 & 3,61 & 10,30 \\
Erythroxilum pulchrum & 6 & 186 & 11 & 101 & 6 & 3,23 & 10,89 & 2,38 & 1,83 & 5,94 & 3,61 & 9,22 \\
Handroanthus cf. & & & & & & & & & & & & \\
umbellata & 5 & 186 & 13 & 101 & 5 & 2,69 & 12,87 & 2,81 & 2,60 & 4,95 & 13,01 & 8,51 \\
Serjania clematidifolia & 5 & 186 & 7 & 101 & 5 & 2,69 & 6,93 & 1,52 & 1,40 & 4,95 & 3,01 & 7,22 \\
Crypthantus sp. & 5 & 186 & 7 & 101 & 5 & 2,69 & 6,93 & 1,52 & 1,40 & 4,95 & 3,01 & 7,22 \\
Pyrostegia venusta & 4 & 186 & 7 & 101 & 4 & 2,15 & 6,93 & 1,52 & 1,75 & 3,96 & 2,41 & 6,08 \\
Bromelia antiacantha & 3 & 186 & 5 & 101 & 3 & 1,61 & 4,95 & 1,08 & 1,67 & 2,97 & 1,81 & 4,50 \\
Morfoespécie 06 & 2 & 186 & 6 & 101 & 2 & 1,08 & 5,94 & 1,30 & 3,00 & 1,98 & 1,20 & 3,58 \\
Bomarea sp. & 2 & 186 & 6 & 101 & 2 & 1,08 & 5,94 & 1,30 & 3,00 & 1,98 & 1,20 & 3,58 \\
Stygmaphyllon ciliatum & 2 & 186 & 4 & 101 & 2 & 1,08 & 3,96 & 0,87 & 2,00 & 1,98 & 1,20 & 3,15 \\
Oeceoclades maculata & 2 & 186 & 3 & 101 & 2 & 1,08 & 2,97 & 0,65 & 1,50 & 1,98 & 1,20 & 2,93 \\
Olyra sp. & 1 & 186 & 3 & 101 & 1 & 0,54 & 2,97 & 0,65 & 3,00 & 0,99 & 0,60 & 1,79 \\
Morfoespécie 08 & 1 & 186 & 3 & 101 & 1 & 0,54 & 2,97 & 0,65 & 3,00 & 0,99 & 0,60 & 1,79 \\
Myrocarpus fastigiatus & 1 & 186 & 2 & 101 & 1 & 0,54 & 1,98 & 0,43 & 2,00 & 0,99 & 0,60 & 1,57 \\
Morfoespécie 07 & 1 & 186 & 2 & 101 & 1 & 0,54 & 1,98 & 0,43 & 2,00 & 0,99 & 0,60 & 1,57 \\
Machaerium sp. & 1 & 186 & 2 & 101 & 1 & 0,54 & 1,98 & 0,43 & 2,00 & 0,99 & 0,60 & 1,57 \\
Croton sp. & 1 & 186 & 1 & 101 & 1 & 0,54 & 0,99 & 0,22 & 1,00 & 0,99 & 0,60 & 1,36 \\
Morfoespécie 01 & 1 & 186 & 1 & 101 & 1 & 0,54 & 0,99 & 0,22 & 1,00 & 0,99 & 0,60 & 1,36 \\
\hline & & & & & & & & & & &
\end{tabular}

Na pastagem foram encontradas sete espécies distribuídas em quatro famílias, sendo a maioria espécies herbáceas anuais (Tabela 1), as quais conseguem se reproduzir aproveitando os recursos do ambiente disponíveis no período de maior precipitação. As plantas anuais são consideradas do tipo investidor, pois usam seus assimilados para ganhar rapidamente abundante matéria orgânica, aproveitando um curto período favorável do ano para crescer, florescer e frutificar (LARCHER, 2004). Ao morrerem, deixam sementes que permanecem latentes até o próximo período favorável à germinação.

Considerando que a área de pastagem permaneceu abandonada desde 1930 (SEMUAM, 2001), pode-se assumir que a sucessão encontra-se estagnada ou em involução, pelo fato de predominarem poucas espécies herbáceas e trepadeiras, indicando haver dificuldade para colonização e estabelecimento de espécies exigentes, formando ecossistemas com baixa diversidade e comunidades simplificadas. Segundo Woodwell (1974), as comunidades simplificadas estão sujeitas a rápidas mudanças na densidade, condicionadas pelas facilidades de reprodução dos organismos, podendo haver perda da estrutura e capacidade de regulação do ecossistema.

$\mathrm{Na}$ floresta, no período de verão, foram amostradas 21 espécies e no inverno, 16, com saída de oito espécies no período de inverno, incluindo-se entre elas trepadeiras $(37,50 \%)$ e arbustivas decíduas $(37,50 \%)$ (Tabela 1), que provavelmente permaneceram no sistema, mas não entraram na amostragem por estarem sem folhas. Segundo Trovão et al. (2007), as plantas desencadeiam estímulos funcionais para sobreviverem em condições de estresse hídrico, tais como modificações anátomo-morfológicas, que incluem, entre outras, desde aprofundamento do sistema radicular, diminuição no tamanho da folha e expansão caulinar até perda de folhas. 
Tabela 4. Parâmetros quantitativos da regeneração espontânea da floresta, para o período de inverno/2008. n: número de indivíduos da espécie; N: número total de indivíduos; NT: número de toques; NP: número de pontos; DR: densidade relativa; VA: vigor absoluto; VR: vigor relativo; MT: média de toques; FA: frequência absoluta; FR: frequência relativa; VI: valor de importância.

Table 4. Quantitative parameters of spontaneous regeneration in the forestry, on the winter period /2008. $\mathrm{n}$ : number of species individuals; N: total individuals number; NT: number of touches; NP: number of points; DR: relative density; VA: absolute vigor; VR: relative vigor; MT: average of touches; FA: absolute frequency; FR: relative frequency; VI: importance value.

\begin{tabular}{lcccccccccccc}
\hline Espécie & $\mathbf{n}$ & $\mathbf{N}$ & $\mathbf{N T}$ & $\mathbf{N T P}$ & $\mathbf{N P}$ & $\mathbf{D R}$ & VA & VR & MT & FA & FR & VI \\
\hline Brosimum guianense & 79 & 146 & 192 & 101 & 64 & 54,11 & 190,10 & 60,00 & 3,00 & 63,37 & 48,86 & 162,97 \\
Samanea sp. & 16 & 146 & 32 & 101 & 16 & 10,96 & 31,68 & 10,00 & 2,00 & 15,84 & 12,21 & 33,17 \\
Acacia plumosa & 11 & 146 & 18 & 101 & 11 & 7,53 & 17,82 & 5,63 & 1,64 & 10,89 & 8,40 & 21,56 \\
Serjania clematidifolia & 7 & 146 & 10 & 101 & 7 & 4,79 & 9,90 & 3,13 & 1,43 & 6,93 & 5,34 & 13,26 \\
Erythroxilum pulchrum & 6 & 146 & 11 & 101 & 6 & 4,11 & 10,89 & 3,44 & 1,83 & 5,94 & 4,58 & 12,13 \\
Eugenia brasiliensis & 4 & 146 & 15 & 101 & 4 & 2,74 & 14,85 & 4,69 & 3,75 & 3,96 & 3,05 & 10,48 \\
Crypthantus sp. & 5 & 146 & 7 & 101 & 5 & 3,42 & 6,93 & 2,19 & 1,40 & 4,95 & 3,82 & 9,43 \\
Handroanthus & & & & & & & & & & & & \\
cf.umbellata & 4 & 146 & 8 & 101 & 4 & 2,74 & 7,92 & 2,50 & 2,00 & 3,96 & 3,05 & 8,29 \\
Prostegia vemusta & 3 & 146 & 7 & 101 & 3 & 2,05 & 6,93 & 2,19 & 2,33 & 2,97 & 2,29 & 6,53 \\
Dalbergia brasiliana & 2 & 146 & 7 & 101 & 2 & 1,37 & 6,93 & 2,19 & 3,50 & 1,98 & 1,53 & 5,08 \\
Machaerium sp. & 2 & 146 & 3 & 101 & 2 & 1,37 & 2,97 & 0,94 & 1,50 & 1,98 & 1,53 & 3,83 \\
Morfoespécie 02 & 2 & 146 & 3 & 101 & 2 & 1,37 & 2,97 & 0,94 & 1,50 & 1,98 & 1,53 & 3,83 \\
Bromelia antiacantha & 2 & 146 & 2 & 101 & 2 & 1,37 & 1,98 & 0,63 & 1,00 & 1,98 & 1,53 & 3,52 \\
Morfoespécie 01 & 1 & 146 & 2 & 101 & 1 & 0,68 & 1,98 & 0,63 & 2,00 & 0,99 & 0,76 & 2,07 \\
Myrocarpus fastigiatus & 1 & 146 & 2 & 101 & 1 & 0,68 & 1,98 & 0,63 & 2,00 & 0,99 & 0,76 & 2,07 \\
Oeceoclades maculata & 1 & 146 & 1 & 101 & 1 & 0,68 & 0,99 & 0,31 & 1,00 & 0,99 & 0,76 & 1,76 \\
\hline
\end{tabular}
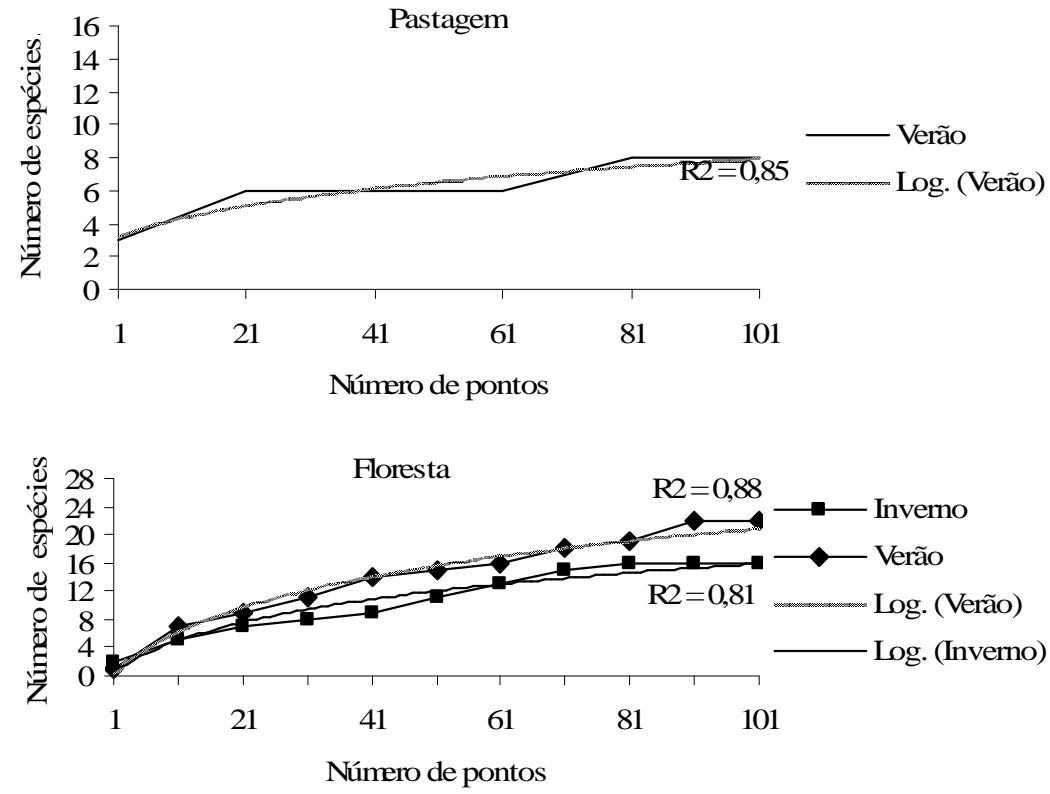

Figura 2. Variação sazonal das espécies da regeneração na pastagem e na floresta. Ajustada pelo modelo logarítmico E.

Figure 2. Seasonal variation of regeneration species in pasture, and in forest. Adjustment by logarithmic E model. 
A maioria das espécies da regeneração permaneceu nas duas estações na área de floresta, indicando adaptação aos efeitos impostos pelas variações pluviométricas, como estresse hídrico e disponibilidade de nutrientes. Elas desenvolveram mecanismos individuais ou coletivos de superar os meses com menor oferta de recursos no ambiente, criando capacidade de resistir às adversidades climáticas e mantendo estrutura autossustentável. Esse fato indica que provavelmente o ecossistema está adquirindo condições para se autodeterminar, sustentando tendência de restauração, ou seja, de continuar evoluindo sucessionalmente.

Considerando o período de verão e inverno para a área de floresta, foram amostradas 7 espécies arbóreas (Handroanthus cf. umbellata (Sond.) Mattos, Erythroxilum pulchrum, Samanea sp., Dalbergia brasiliensis Vogel, Myrocarpus fastigiatus Allemao, Br. guianense, Eugenia brasiliensis Lam.) e 3 arbustivas (Croton sp., Morfoespécie 06 e Morfoespécie 08), responsáveis em manter o dossel, bem como toda a estrutura da floresta, sustentando os processos ecológicos. Esses indivíduos provavelmente serão responsáveis pelo microclima do sub-bosque, alterando a temperatura e a umidade e colaborando para a chegada e estabelecimento de propágulos, geradores de plântulas e indivíduos, capazes de aumentar a resiliência do ambiente. Essas características favorecem o estabelecimento de espécies de estágios sucessionais mais avançados.

Ao longo do ano de estudo, o período de maior precipitação ocorreu nos meses de outubro a março, com maior concentração nos meses de janeiro a março, respectivamente, com 116, 145 e $129 \mathrm{~mm}$ (Figura 3). Já o período de menor precipitação, que correspondeu aos meses secos, foi entre maio e setembro, sendo mais expressivo nos meses de maio, junho e julho, respectivamente, com 28,29 e $15 \mathrm{~mm}$.

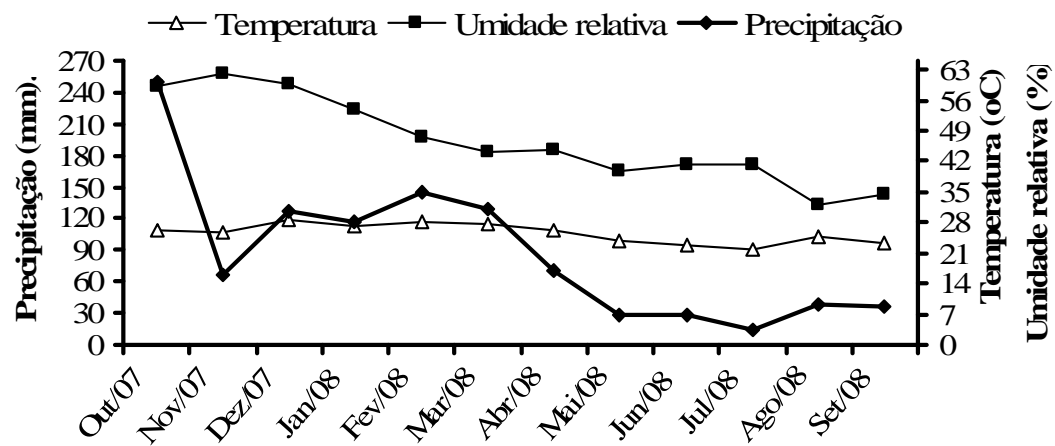

Figura 3. Variáveis climáticas na área de estudo.

Figure 3. Climatic variables in the focused area.

O período de maior variação sazonal ocorreu entre fevereiro e julho (Figura 3), justamente durante os meses em que se promoveram os levantamentos de campo. As mortes das espécies herbáceas anuais, aspecto seco de trepadeiras e gramíneas e abscisão folhar são, portanto, respostas da vegetação às mudanças do regime de chuvas durante o ano. Machado et al. (2009), ao avaliarem a variação fitofisionômica da vegetação nativa, observaram que elas também se mostraram sensíveis às estiagens.

A temperatura média variou pouco ao longo do ano, apresentando amplitude entre $21,7{ }^{\circ} \mathrm{C}$ e $28,6{ }^{\circ} \mathrm{C}$ (Figura 3). A umidade relativa do ar foi maior para os meses de outubro, novembro, dezembro e janeiro $(59,34 ; 62,24 ; 59,49$ e 53,94\%, respectivamente), sofrendo redução de aproximadamente $50 \%$ em relação ao valor máximo para os meses de julho, agosto e setembro (Figura 3). Esses valores apresentaram uma tendência acompanhando a variação da precipitação, provavelmente também interferindo indiretamente na vegetação.

\section{CONCLUSÕES}

- Na pastagem, a baixa diversidade de espécies regenerantes, distribuídas nos grupos de herbáceas $(66,67 \%)$, gramíneas $(16,67 \%)$ e trepadeiras $(16,67 \%)$, e a ocorrência anual de fogo no período de secas tornam evidentes os efeitos da sazonalidade na vegetação, comprometendo a regeneração e a sucessão. Essas características podem indicar um quadro de tendência de degradação do ecossistema. 
- Na floresta, a diversidade das espécies regenerantes (sete de porte arbóreo e três arbustivas), pertencentes aos grupos ecológicos pioneira, secundária inicial e secundária tardia, associada ao decréscimo de oito espécies no período de estiagem (trepadeiras e arbustivas decíduas), sinaliza adaptação das espécies permanentes ao sistema ecológico, condição básica que evidencia maior resiliência do ecossistema, favorável para que ocorram processos de restauração espontânea.

- A coleta de dados com séries históricas prolongadas poderá aperfeiçoar os estudos sobre efeitos das estiagens na manutenção das espécies e das suas respectivas tendência de restauração dos ecossistemas.

\section{AGRADECIMENTOS}

À FAPERJ (Fundação Carlos Chagas Filho de Amparo à Pesquisa do Estado do Rio de Janeiro), pela bolsa de mestrado à primeira autora, e à Vigne Ltda., pela permissão em usar área do Plano de Restauração de Áreas Degradadas.

\section{REFERÊNCIAS}

ANGIOSPERM PHYLOGENY GROUP (APG). An update of the Angiosperm Phylogeny Group classification for the orders and families of flowering plants: APG II. Botanical Journal of the Linneam Society, London, v.141, p. 399 - 436, 2003.

BRASIL. Ministério do Meio Ambiente (MMA). Lei n. 9.985, de 18 de julho de 2000. Diário Oficial da União, 19 jul. 2000. Disponível em: <http://www.mma.gov.br/port/conama/legiabre.cfm?codlegi=322>. Acesso em: 17/02/2009.

BULLOCK, S. H. Plant reproduction in neotropical dry forests. In: BULLOCK, H.; MOONEY, A.; MEDINA, E. (eds.). Seasonally dry tropical forests. Cambridge: University Press, 1995. p. 277 - 296.

CAIRNS JÚNIOR, J.; HECKMAN, J. R. Restoration ecology: the state of an emerging field. Restoration Ecology, Arizona, v. 21, p. 167 - 189, 1996.

CARPANEZZI, A. A. Fundamentos para a reabilitação de ecossistemas floretais. In: GALVÃO, A. P. M.; SILVA, V. P. (eds.). Restauração florestal: fundamentos e estudos de caso. Colombo: Embrapa Florestas, 2005. p. 27 - 45.

CARVALHO, P. E. R. Técnicas de recuperação e manejo de áreas degradadas. In: Galvão, A. P. M. (org.). Reflorestamento de propriedades rurais para fins produtivos e ambientais: um guia para ações municipais e regionais. Brasília: Embrapa, 2000. p. 251 - 268.

COATES, K. D.; BURTON, P. J. A gap-based approach for development of silvicultural systems to address ecosystem management objectives. Forest Ecology and Management, Amsterdam, v. 99, p. 337 - 354, 1997.

CORTINES, E. Avaliação da sustentabilidade ecológica de plantios realizados em ecossistemas perturbados, Nova Iguaçu - RJ. 61 p. Monografia (Bacharel em Ciências Biológicas) - Universidade Federal Rural do Rio de Janeiro, Seropédica, 2005.

CURTIS, J. T. The vegetation of Wisconsin: an ordination of plant communities. Madison: University of Wisconsin Press, 1959. 657 p.

DREW, D. O homem e o ambiente: introdução. In: Processos interativos homem-meio ambiente. 6 ed. Rio de Janeiro: Bertrand Brasil, 2005. p. 1 - 42.

ENGEL, V. L.; PARROTTA, J. A. Definindo restauração ecológica; tendências e perspectivas mundiais. In: KAGEYAMA, P. Y.; OLIVEIRA, R. E. de; MORAES, L. F. D. de; ENGEL, V. L.; GANDARA, F. B. (orgs.). Restauração ecológica de ecossistemas naturais. Botucatu: FEPAF, 2008. p. 1 - 26.

FUNDAÇÃO INSTITUTO DE DESENVOLVIMENTO ECONÔMICO E SOCIAL DO RIO DE JANEIRO (FIDERJ). Indicadores climatológicos do Estado do Rio de Janeiro. Rio de Janeiro: FIDERJ,1978. 156 p. 
GAMA, J. R. V.; BOTELHO, S. A.; BENTES-GAMA, M. M.; SCOLFORO, J. R. S. Estrutura e potencial futuro de utilização da regeneração natural de floresta de várzea alta no município de Afuá, Estado do Pará. Ciência Florestal, Santa Maria, v. 13, n. 2, p. 71 - 82, 2003.

GANDOLFI, S.; LEITÃO-FILHO, H. F.; BEZERA, C. L. F. Levantamento florístico e caráter sucessional das espécies arbustivo-arbóreas de uma floresta mesófila semidecídua no município de Guarulhos, SP. Revista Brasileira de Biologia, São Carlos, v. 55, n. 4, p. 753 - 767, 1995.

GUEDES-BRUNI, R. R. Composição, estrutura e similaridade florística de dossel em seis unidades de Mata Atlântica no Rio de Janeiro. 231 p. Tese (Doutorado em Ecologia) - Universidade de São Paulo, São Paulo, 1998.

INSTITUTO BRASILEIRO DE GEOGRAFIA E ESTATÍSTICA (IBGE). Manual técnico da vegetação brasileira. Rio de Janeiro: Fundação Inst. Brasileiro de Geografia e Estatística/DERNA, 1992. 92 p. (Manuais Técnico de Geociências 1).

JANZEN, D. H. Ecologia vegetal nos trópicos. São Paulo: EPU, 1980. 79 p.

KAGEYAMA, P. Y.; GANDARA, F. B. Resultados do programa de restauração com espécies arbóreas nativas do convênio ESALQ/USP e CESP. In: GALVÃO, A. P. M.; SILVA, V. P. (eds.). Restauração florestal: fundamentos e estudos de caso. Colombo: Embrapa Florestas, 2005. p. 47 - 58.

KOZLOWSKI, T. T. Physiological ecology of natural regeneration of harvested and disturbed forest stands: implications for forest management. Forest Ecology and Management, v. 158, p. 195 - 221, 2002.

KREBS, C. J. Ecology: the experimental analysis of distribution and abundance. 2. ed. New York: Harper \& Row, 1978. 678 p.

LARCHER, W. Ecofisiologia vegetal. São Carlos: RiMa, 2004. 531 p.

LORENZI, H. Árvores brasileiras: manual de identificação e cultivo de plantas arbóreas nativas do Brasil. 4. ed. São Paulo: Nova Odessa, v. 1, 2002. 368 p.

LUMBRERAS, J. F.; NAIME, U. J.; CARVALHO FILHO, A. Zoneamento agroecológico do Estado do Rio de Janeiro. Rio de Janeiro: Embrapa Solos, 2003. 113 p. (Boletim de Pesquisa e Desenvolvimento, n. 33).

MACHADO, L. E. G.; NUNES, E. D.; ROMÃO, P. A. Análise da influência da topografia na variação sazonal de fitofisionomias na bacia do Rio Veríssimo - GO. In: SIMPÓSIO BRASILEIRO DE SENSORIAMENTO REMOTO, 14., 2009, Natal. Anais... Natal: INPE, 2009. p. 2817 - 2822.

MANTOVANI, W. Análise florística e fitossociológica do estrato herbáceo-subarbustivo do cerrado na reserva biológica de Mogi-Guaçu e em Itirapina, SP. 166 p. Tese (Doutorado em Ecologia) Universidade Estadual de Campinas, Campinas, 1987.

MARTINS, S. V.; GLERIANI, J. M.; AMARAL, C. H.; RIBEIRO, T. M. Caracterização do dossel e do estrato de regeneração natural no sub-bosque e em clareiras de uma Floresta Estacional Semidecidual no Município de Viçosa, MG. Revista Árvore, Viçosa, v. 32, n. 4, p. 759 - 767, 2008.

MATTEUCCI, S. D.; COLMA, A. Metodologia para el estudio de la vegetación. Washington: Secretaria General de la OEA, 1982. 169 p.

MATTOS, C. C. L. V.; SILVA, M. A. R.; OLIVEIRA, M. N.; COMBAT, I. B. Boletim agrometeorológico, UFRRJ-1996. Floresta e Ambiente, Seropédica, v. 5, n. 1, p. 208 - 215, 1998.

PARKER, V. T. The scale of successional models and restoration objectives. Restoration Ecology, Arizona, v. 5, n. 4, p. 301 - 306, 1997.

POGGIANI, F.; REZENDE, G. C.; SUITER FILHO, W. Efeitos do fogo na brotação e crescimento de Eucalyptus grandis após o corte raso e as alterações nas propriedades do solo. IPEF, Piracicaba, n. 24, p. $33-42,1983$. 
PREFEITURA MUNICIPAL DE NOVA IGUAÇU (PMNI). Povoamento: a história do Brasil passa por aqui. Disponível em: <http://www.novaiguacu.rj.gov.br/pdf/histórico_nova_iguacu.pdf>. Acesso em: $16 / 05 / 2007$.

REIS-DUARTE, R. M.; GALVÃO-BUENO, M. S. Interação solo x planta x animal: uma contribuição para recuperação de áreas degradadas. In: CONGRESSO NACIONAL DE BOTÂNICA, 58., 2007, São Paulo. Anais... São Paulo: Sociedade Botânica do Brasil, 2007. p. 534 - 536.

RIBEIRO, G. H. P. M.; FELFILI, J. M. Regeneração natural em diferentes ambientes da Mata de Galeria do Capetinga, na Fazenda Água Limpa - DF. Revista Cerne, Lavras, v. 15, n.1, p. 1 - 9, 2009.

RODRIGUES, R. R.; GANDOLFI, S.; NAVE, A. G.; ATTANASIO, C. M. Atividades de adequação ambiental e restauração florestal do LERF/ESALQ/USP. Pesquisa Florestal Brasileira, Colombo, n. 55, p. 7 - 21, 2007.

ROSOT, N. C.; DLUGOSZ, F. L.; ROSOT, M. A. D.; KURASZ, G.; OLIVEIRA, Y. M. M. Ações de recuperação em área degradada por fogo em Floresta Ombrófila Mista: resultados parciais. Pesquisa Florestal Brasileira, Colombo, n. 55, p. 23 - 30, 2007.

SATTLER, D.; LINDNER, A.; MORAWETZ, W. A função da sazonalidade no levantamento estrutural de uma floresta montana tropical no Rio de Janeiro, Brasil. In: CRONEMBERGER, C.; VIVEIROS DE CASTRO, E. B. (orgs.). Ciência e conservação na Serra dos Órgãos. Brasília: Ibama, 2007. p. 106 - 116.

SECRETARIA MUNICIPAL DE URBANISMO E MEIO AMBIENTE (SEMUAM). Parque Municipal de Nova Iguaçu: plano de manejo. Nova Iguaçu: PCNI, FEMA, IEF, 2001. 102 p.

SILVA, J. A.; LEITE, E. J.; SILVEIRA, M.; NASSIF, A. A.; REZENDE, S. J. M. Caracterização florística, fitossociológica e regeneração natural do sub-bosque da Reserva Genética Florestal Tamanduá DF. Ciência Florestal, Santa Maria, v. 14, n. 1, p. 121 - 132, 2004.

SPOLIDORO, M. L. C. V. Fatores ambientais que afetam a distribuição e frequência de capinzais na Serra do Madureira - Mendanha, Rio de Janeiro. 75 p. Monografia (Especialização em Ciências Ambientais) - Universidade Federal Rural do Rio de Janeiro, Seropédica, 1998.

TRIBUNAL DE CONTAS REGIONAL DO ESTADO DO RIO DE JANEIRO (TCE-RJ). Estudo socioeconômico, Nova Iguaçu. Rio de Janeiro: Secretaria Geral de Planejamento, 2007. 153 p.

TROVÃO, D. M. B. M.; FERNANDES, P. D.; ANDRADE, L. A.; DANTAS NETO, J. Variações sazonais de aspectos fisiológicos de espécies da Caatinga. Revista Brasileira de Engenharia Agrícola e Ambiental, Campina Grande, v. 11, n. 3, p. 307 - 311, 2007.

VACCARO, S.; LONGHI, S. J.; BRENA, D. A. Aspectos da composição florística e categorias sucessionais do estrato arbóreo de três subseres de uma Floresta Estacional Decidual no município de Santa Tereza - RS. Ciência Florestal, Santa Maria, v. 9, n. 1, p. 1 - 18, 1999.

VIEIRA, D. L. M.; SCARIOT, A. Principles of natural regeneration of Tropical Dry Forests for restoration. Restoration Ecology, Arizona, v. 14, n. 1, p. 11 - 20, 2006.

WOODWELL, G. M. O ciclo da energia na biosfera. In: A Biosfera. São Paulo: Universidade de São Paulo, 1974. p. 26 - 38. 